\title{
Role of Erbium: YAG Laser in management of cutaneous warts
}

Rohan Bhattacharjee ${ }^{1}$, Imran Pathan ${ }^{2}$, Ravi Kumar Chittoria ${ }^{2}$

${ }^{1}$ Department of Dermatology and STD, JIPMER.

${ }^{2}$ Department of Plastic Surgery, JIPMER.

*Corresponding Author: Ravi Kumar Chittoria, Professor, Department of Plastic Surgery, JIPMER, Puducherry, India.

Received date: June 03, 2021; Accepted date: June 14, 2021; Published date: June 17, 2021

Citation: R Bhattacharjee, I Pathan, RK Chittoria. (2021) Tyrosine kinase inhibitors in dermatology: A systemic review. J. Dermatology and Dermatitis. 6(2); Doi: 10.31579/2578-8949/077

Copyright: (C2021 Ravi Kumar Chittoria, This is an open-access article distributed under the terms of The Creative Commons. Attribution License, which permits unrestricted use, distribution, and reproduction in any medium, provided the original author and source are credited.

\begin{abstract}
Cutaneous warts are one of the commonest presenting complaints of patients reporting to Dermatology OPD. Most of the warts are viral in origin and they can be either single or multiple. Their morphology varies from flat-topped, angulated, filiform etc [1]. Nowadays, various options are available for management of warts which include topical application of medications, surgical excision and laser treatment. Conventionally, $\mathrm{CO}_{2}$ laser has been used for treatment of warts but Erbium: yttrium aluminium-garnet (YAG) laser is one of the lasers which has recently come into the literature for treatment of warts. This study highlights our experience of using of Erbium: YAG laser in the management of cutaneous warts.
\end{abstract}

Keywords: warts; Erbium-YAG laser

\section{Introduction:}

Cutaneous warts are one of the commonest presenting complaints of patients reporting to Dermatology OPD. Most of the warts are viral in origin and they can be either single or multiple. Their morphology varies from flat-topped, angulated, filiform etc [1]. Nowadays, various options are available for management of warts which include topical application of medications, surgical excision and laser treatment. Conventionally, $\mathrm{CO}_{2}$ laser has been used for treatment of warts but Erbium: yttrium aluminium-garnet (YAG) laser is one of the lasers which has recently come into the literature for treatment of warts. This study highlights our experience of using of Erbium: YAG laser in the management of cutaneous warts.

\section{Case history}

This study was conducted collaboratively in the departments of Dermatology and Plastic surgery. The patient was a 35-year-old Indian male, an electrician by occupation who presented with am asymptomatic growth over the left index finger for one-year duration which was gradually increasing in size. On examination, there was a pinkish coloured, well defined plaque of size $4 \mathrm{~mm} \times 2 \mathrm{~mm}$ located over the ulnar aspect of the junction of the middle and distal phalanx and with a verrucous surface (figure-1). A diagnosis of palmar wart was made. There was no history of any known comorbid illness or any contraindication to laser procedure in the patient. An informed consent was obtained from the patient and the patient was planned to undergo a session of Erbium: YAG laser treatment.

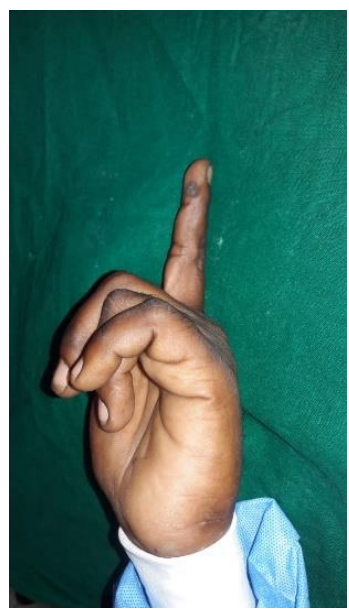

Figure 1: Verruca vulgaris over the left index finger

We used Quanta system Q1, Twain Erbium: YAG 2940 nm Laser system with the following specifications: fluence- $5 \mathrm{~J} / \mathrm{cm}^{2}$, spot size of $4 \mathrm{~mm}$, pulse width of 0.3 milli seconds and a frequency of $6 \mathrm{~Hz}$ (figure-2). These were the parameters suggested in the manual provided along with the laser device system for treatment of cutaneous warts. After preparation of the operative area and after precooling with a coolant device, we delivered a single shot of laser pulse while using a suction system to evacuate the plume and while all the personnel and patient were wearing protective 
goggles. After that the area was dressed with mupirocin ointment. The patient was followed up after 48 hours and then after a week and then after 4 weeks. Patient was advised daily application of mupirocin ointment over the wound site.

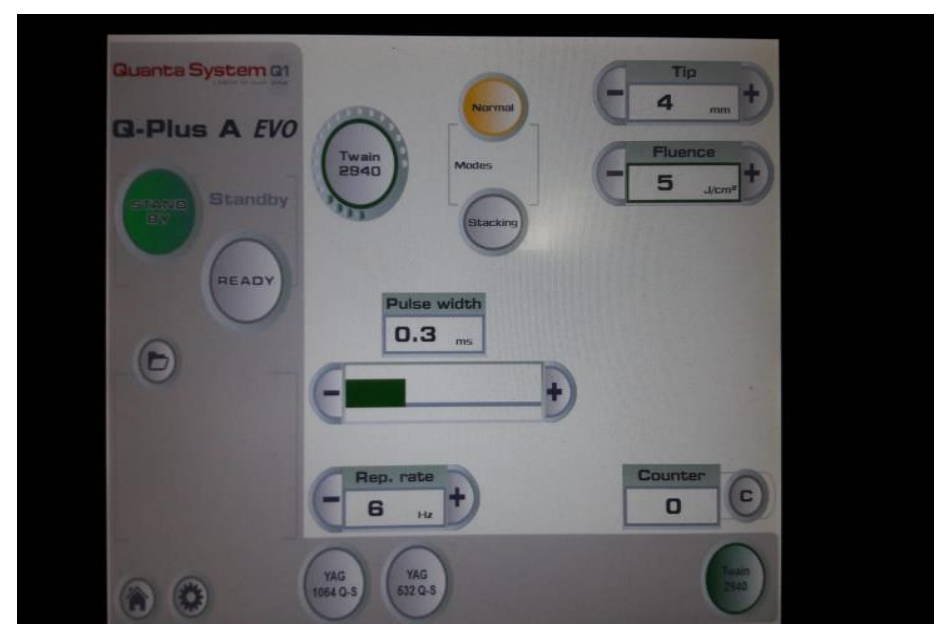

Figure-2: Parameters of Erbium:YAG laser which were set for the treatment of wart

\section{Observation:}

After 48 hours, the wart had completely resolved and the scab had fallen off leaving a small raw area covered with crust. After 1 week, the area had healed (figure-3) and patient had no recurrences till the end of one month of follow up. No early or late post-operative complications were noted.

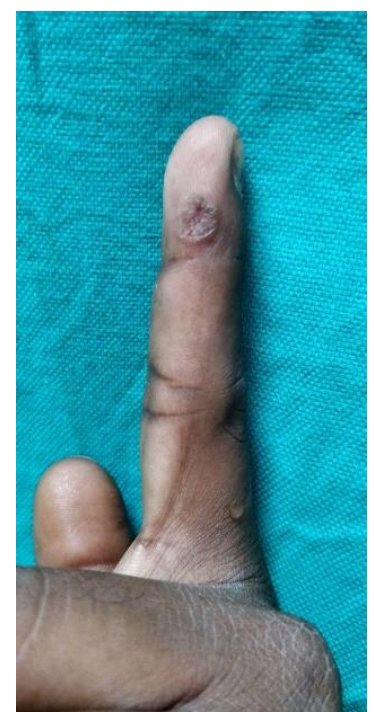

Figure 3: Follow up after 7 days of Laser procedure.

\section{Discussion:}

Verruca vulgaris is the most common type of cutaneous warts and the causative agent is Human papilloma virus (HPV). The various types implicated in the causation of common warts are HPV type 2, 27, 57. Other than verruca vulgaris, palmar, plantar, plane warts are other types of cutaneous. HPV types 1 and 63 are implicated in the causation of palmar and plantar warts. Palmar warts are usually preceded by a history of trauma and are usually asymptomatic and untreated warts clear spontaneously within 2 years and few may persist till 4 years. ${ }^{[1]}$ Evidence exists for treatment of warts using cryotherapy with a clearance rate of up to $69 \%$, using ablative lasers like $\mathrm{CO}_{2}$ and pulsed dye laser with a clearance rate of $47-90 \%$ [2].

Erbium: YAG laser is a solid-state crystal laser and is primarily used for ablative purposes. Water acts as a chromophore for this laser similar to $\mathrm{CO}_{2}$ laser and acts via photoacoustic mechanism causing vaporization followed by phase explosion [3]. It is more selective for water than $\mathrm{CO}_{2}$ laser. ${ }^{[2]}$ In contrast to $\mathrm{CO}_{2}$ laser, the Erbium: YAG laser provides with better precision and minimal adjacent tissue damage and better healing [3]. Erbium: YAG laser provides with the ability to ablate large surface areas and allows for deeper circumscribed lesions to be removed. Unlike the plume generated during treatment of warts with electrodessication and $\mathrm{CO}_{2}$ laser, the plume generated while using Er: YAG laser doesn't contain any viral particles and hence doesn't carry any risk of infection $[2,4,5]$.

Literature search showed case reports of use of Erbium: YAG laser for treatment of perioral warts with complete resolution of the lesion and with no post-operative complications. ${ }^{[6]}$ Balevi et al [7] conducted a randomised controlled study on 46 patients with recalcitrant facial verruca plana and used Er: YAG laser to treat the warts and noted complete response (100\% clearance of lesion) in $62.5 \%$ of patients. Wollina et al [2] reported using Erbium: YAG laser for periungual or plantar warts in 69 patients and obtained a complete response with a single treatment session in $72.5 \%$ of patients.

In the current study we report that there is definitely a role of Erbium: YAG laser in the management of cutaneous warts and more specifically of palmar warts with minimal damage to the adjacent tissue.

\section{Conclusion:}

We conclude that there is definitely a role of Erbium: YAG laser in the management of cutaneous warts and there is a paucity of studies reporting the use of Erbium: YAG laser in management of warts from India and hence this report can be considered as a novel case report. This report is limited by being a single centre case report and hence multicentric randomised controlled studies are needed to substantiate the results of this study.

\section{Disclosure:}

No conflicts of interest.

\section{Financial support:}

Department of Plastic surgery and Department of Dermatology and STD.

\section{References:}

1. Kang S,Amagai M, Bruckner AL, Enk AH, Margolis DJ, McMichael AJ, Orringer JS. (2019) Fitzpatrick's dermatology. Ninth edition. New York: McGraw-Hill Education: 3098-3106

2. Wollina U, Konrad H, Karamfilov T. (2001) Treatment of common warts and actinic keratoses by Er:YAG laser. Journal of Cutaneous Laser Therapy;3(2):63-6.

3. Wollina U. (2016) Erbium-YAG laser therapy - analysis of more than 1,200 treatments. Global Dermatology; 3(2):268-72.

4. Kaufmann R, Beier C. (2001) Erbium:YAG Laser Therapy of Skin Lesions. Medical Laser Application; 16(4):252-63.

5. Atrelles M, Allones I, Mayo E. (2006) Er:YAG Laser Ablation of Plantar Verrucae with Red LED Therapy-Assisted Healing. Photomedicine and Laser Surgery; 24(4):494-8.

6. Pescatore AM. (2016) CASE REPORT: Socially Disabling Warts. Journal of the Laser and Health Academy;1:27-29

7. Balevi A, Üstüner P, Özdemir M. (2017) Use of Er:YAG for the treatment of recalcitrant facial verruca plana. Journal of Dermatological Treatment; 28(4):368-71. 